\title{
The deep vein thrombosis of lower limb after total hip arthroplasty: what should we care
}

\author{
Xinyan $\mathrm{Yu}^{1}$, Yingying $\mathrm{Wu}^{1}$ and Rende Ning ${ }^{1,2^{*}}$
}

\begin{abstract}
Background: Deep vein thrombosis (DVT) of lower limb is one of the common complications after total hip arthroplasty(THA), we aimed to evaluate the potential risk factors of DVT of lower limb in patients with THA, to provide insights into the management of THA.

Methods: Patients who underwent THA in our hospital from January 1, 2017 to November 30, 2020 were included. The personal characteristics and clinical data of DVT and no-DVT patients were compared and analyzed. Logistic regression analyses were perfomed to identify the potential risk factors of DVT in patients with THA.

Results: A total of 182 THA patients were included, the incidence of DVT of lower limb in patients with THA was $19.78 \%$. There were significant differences in the age, BMI, diabetes, number of replacement, duration of surgery, type of prosthesis and duration of days in bed between DVT and no-DVT patients(all $P<0.05$ ). And there were no significant differences in the gender, hypertension, hyperlipidemia, preoperative D-dimer, type of anesthesia and anticoagulant drugs use(all $P>0.05)$. Logistic regression analysis indicated that age $>70 y(O R 4.406,95 \% \mathrm{Cl} 1.744 \sim$ 6.134), $\mathrm{BMI} \geq 28(\mathrm{OR} 2.275,95 \% \mathrm{Cl} 1.181 \sim 4.531)$, diabetes(OR3.949, $95 \% \mathrm{Cl} 1.284 \sim 5.279)$, bilateral joint replacements(OR2.272, $95 \% \mathrm{Cl} 1.402 \sim 4.423)$, duration of surgery $\geq 120 \mathrm{~min}(\mathrm{OR} 3.081,95 \% \mathrm{Cl} 1.293 \sim 5.308)$, cemented prosthesis(OR2.435, $95 \% \mathrm{Cl1} .104 \sim 4.315)$, and duration of days in bed $>3$ days(OR1.566, $95 \% \mathrm{Cl} 1.182 \sim 1.994)$ were the risk factors of DVT of lower limb in patients with THA.

Conclusions: DVT in the lower limb after THA is common, and its onset is affected by many factors. In clinical work, attention should be paid to identify the risk factors for DVT and targeted interventions are highlighted to prevent the postoperative DVT.
\end{abstract}

Keywords: deep vein thrombosis, total hip arthroplasty, management, nursing, care

\section{Background}

Total hip arthroplasty (THA) is a common surgical treatment in the department of orthopedics and one of the effective treatments for end-stage hip joint diseases, mainly for the elderly[1]. THA is mainly used to treat joint pain and dysfunction caused by hip joint disease, including

\footnotetext{
*Correspondence: rendening@yeah.net

1 Department of nursing, The Third Affiliated Hospital of Anhui Medical University, No. 390 Huaihe Road, 230061 Hefei City, Anhui Province, China 2Department of nursing, Shannan people's Hospital, Sare Road, Naidong District, Shannan City 856011, Tibet Autonomous Region, China
}

hip joint osteoarthritis, femoral head necrosis, bone neck fractures and so on[2]. At present, more than 500,000 people worldwide receive artificial joint replacement due to fractures, osteoarthritis, bone tumors and other diseases each year[3]. In China, 30,000 to 50,000 people undergo THA every year $[4,5]$. Through artificial hip replacement, it can relieve joint pain, improve joint function, and correct deformity. And with proper postoperative functional exercise, the patient's hip joint function may meet the needs of daily life and improve the quality of life[6].

(c) The Author(s). 2021 Open Access This article is licensed under a Creative Commons Attribution 4.0 International License, which permits use, sharing, adaptation, distribution and reproduction in any medium or format, as long as you give appropriate credit to the original author(s) and the source, provide a link to the Creative Commons licence, and indicate if changes were made. The images or other third party material in this article are included in the article's Creative Commons licence, unless indicated otherwise in a credit line to the material. If material is not included in the article's Creative Commons licence and your intended use is not permitted by statutory regulation or exceeds the permitted use, you will need to obtain permission directly from the copyright holder. To view a copy of this licence, visit http://creativecommons.org/licenses/by/4.0/ The Creative Commons Public Domain Dedication waiver (http://creativecommons.org/publicdomain/zero/1.0/) applies to the data made available in this article, unless otherwise stated in a credit line to the data. 
Deep venous thrombosis (DVT) is a common complication after hip arthroplasty, with an incidence rate of $40-60 \%[7]$. The formation of DVT of the lower extremities can increase the suffering of patients, prolong hospitalization time, and increase medical expenses[8]. Once it falls off, it can easily cause pulmonary embolism, and severe cases can lead to death. The relevant guidelines $[9,10]$ point out that patients who have undergone major operations such as hip replacement without obvious bleeding tendency need to use anticoagulant drugs within $24 \mathrm{~h}$ after surgery, but there are still some patients who have DVT under the condition of standardized anticoagulant application. At present, there are many reports $[11,12]$ on DVT of the lower extremities after THA at home and abroad, but there are few studies on systemic analysis of DVT after artificial hip replacement, and the risk factors reported in related studies are relatively limited. It is necessary to further explore the related risk factors. Therefore, in this present study, we aimed to evaluate the influencing factors of DVT of lower limb after THA, to provide evidence support for the prevention and treatment of clinical THA.

\section{Methods}

\section{Ethical issues}

In this study, all methods were performed in accordance with the relevant guidelines and regulations. Our study had been verified and approved by the ethics committee of The Third Affiliated Hospital of Anhui Medical University (No.1,700,342), and all the included patients had signed the written informed consents.

\section{Patients}

Patients who underwent THA in our hospital from January 1, 2017 to November 30, 2020 were selected as the research population. The inclusion criteria of patients in our study were: (1) The patient met the criteria for hip replacement and underwent the first THA in our hospital; (2) The age was $\geq 50$ years old, regardless of gender; (3) Preoperative color Doppler ultrasound indicated that there was no DVT in both lower extremities during the examination; (4) The patient's medical record was complete and available for data analysis. The exclusion criteria for patients were: (1) the pathological fractures caused by malignant tumors, tuberculosis which might influence the development of DVT; (2) DVT of the lower extremities existed before THA; (3) patients who disagreed to participate in this study.

\section{The diagnosis of DVT of lower extremity}

The diagnosis of lower extremity DVT was based on the standards in the relevant diagnosis and treatment guidelines[13, 14]. Postoperative observation of the affected limbs for the following manifestations including limb swelling, pain, elevated skin temperature, skin color changes, venous return disorder, Homans sign, Neuhof's sign. Color Doppler ultrasound indicated that there was no color blood flow signal and spectrum signal in the venous cavity, no collapse of the venous pressurized lumen, extremely low echo in the venous lumen, and irregular pulse Doppler spectrum. The ultrasound was generally used in the surgical leg, and if there were abnormal symptoms in another leg, we would also detect it for DVT. The inspection area for ultrasound scanning was from inguinal ligament to the distal leg. Patients underwent ultrasound examination every two days after surgery. And if necessary, the venography was performed.

\section{DVT preventions}

We routinely conducted the mechanical post-operative DVT preventions for all patients as previous report[15]. We would encourage patients get out of bed as early as possible, and to massage the lower limb frequently and observe the status regularly. Besides, all the patients accepted the electrical stimulation for four days with Deming X100 massager(Deming biotechnology company, Wuxi, China), the massage started within $12 \mathrm{~h}$ after operation. The frequency was $30 / 50 / 30$, the pulse width was $400 / 360 / 410$, the massage continued $30 \mathrm{~min}$ each time. Besides, the intensity of stimulation was given differently based on the tolerance of patient, and it was set to the maximum intensity that could be tolerated by patients without discomfort. Besides, $10 \mathrm{mg}$ per day of Rivaroxaban and $0.4 \mathrm{ml}$ of Low-molecular weight heparin calcium was used for the prevention of DVT.

\section{Data collection}

We reviewed patients' medical records, and we collected the general patient information including gender, age, body mass index(BMI), personal history, comorbid diseases, surgical factors including prosthesis type, duration of surgery, anesthesia method, postoperative factors including postoperative days in bed, anticoagulant drug application and laboratory indicators including preoperative D-dimer. Then we observed and analyzed the correlation between the above data and DVT.

\section{Data analysis}

The observed data are statistically analyzed using SPSS23.0 statistical software. The measurement data are all expressed as mean \pm standard deviation or percentage. According to the difference in the nature of each data, chi-square test, $t$-test were applied to identify the difference of DVT and no-DVT group. And logistic regression analyses were conducted to identify the potential risk factors of DVT in patients with THA. $P<0.05$ indicated that the difference was statistically significant. 


\section{Results}

The characteristics of included patients

A total of 182 THA patients were included, of whom 36 patients had suffered from DVT of lower limb, the incidence of DVT of lower limbs in patients with THA was $19.78 \%$. Of the 36 cases of DVT, there were 15 cases of proximal DVTs and 21 cases of distal DVTs. As presented in Table 1, there were significant differences in the age, BMI, diabetes, number of replacement, duration of surgery, type of prosthesis and duration of days in bed between DVT and no-DVT patients(all $P<0.05)$. And there were no significant differences in the gender, hypertension, hyperlipidemia, preoperative D-dimer, type of anesthesia and anticoagulant drugs use (all $P>$ $0.05)$.

\section{The risk factors of DVT in patients with THA}

We included the factors that were found to be significant differences between two group into further logistic regression, and the variable assignments of logistic regression were showed in Table 2.

As indicated in Table 3, The logistic regression analysis found that age $>70 y(O R 4.406,95 \%$ CI1.744 6.134), $\quad \mathrm{BMI} \geq 28(\mathrm{OR} 2.275, \quad 95 \quad \% \mathrm{CI} 1.181 \sim 4.531)$,
diabetes(OR3.949, $95 \%$ CI1.284 5.279), bilateral joint replacements(OR2.272, $95 \% \mathrm{CI} 1.402 \sim 4.423)$, duration of surgery $\geq 120 \min (\mathrm{OR} 3.081,95 \% \mathrm{CI} 1.293 \sim 5.308)$, cemented prosthesis(OR2.435, $95 \% \mathrm{CI} 1.104 \sim 4.315)$, and duration of days in bed $>3$ days(OR1.566, $95 \%$ CI1.182 $\sim 1.994$ ) were the risk factors of DVT of lower limb in patients with THA.

\section{Discussions}

DVT is a disorder of venous return caused by abnormal blood coagulation in the deep veins of the lower extremities, which completely or incompletely obstruct the blood vessels[16]. It is a common complication after THA and an important cause of unexpected deaths during the perioperative period of such patients[17]. Therefore, DVT has attracted extensive attention from clinical medical workers. Studies[18-20] have shown that the incidence of DVT in patients treated with THA is 14.13$20.18 \%$. The results of this study indicate that the incidence of lower limb DVT in patients after THA is $19.78 \%$, which is lower than the previous report[21, 22]. It may be related to the differences in the conditions of included patients, surgical method and perioperative preventive anticoagulation treatment amongst different studies.

Table 1 The characteristics of included patients

\begin{tabular}{|c|c|c|c|c|}
\hline Variables & DVT group $(n=36)$ & Non-DVT group $(n=146)$ & $x^{2} / t$ & $\mathbf{P}$ \\
\hline Male/female & $20 / 16$ & $92 / 54$ & 1.046 & 0.102 \\
\hline Age(y) & $72.14 \pm 8.02$ & $68.11 \pm 9.35$ & 4.328 & 0.025 \\
\hline $\mathrm{BMI}\left(\mathrm{kg} / \mathrm{m}^{2}\right)$ & $28.26 \pm 4.55$ & $26.02 \pm 3.29$ & 3.144 & 0.032 \\
\hline Diabetes & $19(52.78 \%)$ & $25(17.12 \%)$ & 1.118 & 0.009 \\
\hline Hypertension & $21(58.33 \%)$ & 77(52.71\%) & 1.207 & 0.068 \\
\hline Hyperlipidemia & $10(27.78 \%)$ & $42(28.77 \%)$ & 1.084 & 0.106 \\
\hline Preoperative D-dimer (mg/L) & $0.69 \pm 0.11$ & $0.66 \pm 0.12$ & 1.230 & 0.074 \\
\hline \multicolumn{5}{|l|}{ Number of replacement joints } \\
\hline Unilateral & $11(30.56 \%)$ & $38(26.03 \%)$ & 1.140 & 0.031 \\
\hline Bilateral & $25(69.44 \%)$ & $108(73.97 \%)$ & & \\
\hline Duration of surgery(min) & $133.62 \pm 30.18$ & $102 \pm 27.42$ & 9.124 & 0.015 \\
\hline \multicolumn{5}{|l|}{ Type of Anesthesia } \\
\hline General anesthesia & $16(44.44 \%)$ & $68(46.57 \%)$ & 1.122 & 0.078 \\
\hline Epidural anesthesia & $20(55.56 \%)$ & $78(53.42 \%)$ & & \\
\hline \multicolumn{5}{|l|}{ Type of prosthesis } \\
\hline Biological prosthesis & $6(16.67 \%)$ & $72(49.32 \%)$ & 1.205 & 0.036 \\
\hline Cemented prosthesis & $30(83.33 \%)$ & $74(50.68 \%)$ & & \\
\hline Duration of days in bed & $4.24 \pm 1.22$ & $2.79 \pm 1.02$ & 1.177 & 0.042 \\
\hline \multicolumn{5}{|l|}{ Anticoagulant drugs } \\
\hline Rivaroxaban & $22(61.11 \%)$ & $85(58.22 \%)$ & 1.145 & 0.103 \\
\hline Low-molecular weight heparin calcium & 14(38.89\%) & $61(41.78 \%)$ & & \\
\hline
\end{tabular}


Table 2 The variable assignments of logistic regression

\begin{tabular}{lll}
\hline Factors & Variables & Assignment \\
\hline VTE & $Y$ & Yes $=1$, no $=2$ \\
Age $(\mathrm{y})$ & $X_{1}$ & $\geq 70=1,<70=2$ \\
BMI $\left(\mathrm{kg} / \mathrm{m}^{2}\right)$ & $X_{2}$ & $\geq 28=1,<28=2$ \\
Diabetes & $X_{3}$ & Yes $=1$, No $=2$ \\
Number of replacement joints & $X_{4}$ & Bilateral $=1$, unilateral $=2$ \\
Duration of surgery(min) & $X_{5}$ & $\geq 120=1,<120=2$ \\
Type of prosthesis & $X_{6}$ & Cemented prosthesis $=1$, biological prosthesis $=2$ \\
Duration of days in bed & $X_{7}$ & $\geq 3=1,<3=2$ \\
\hline
\end{tabular}

Endometrial injury, venous blood flow stasis and blood hypercoagulability are the three factors that induce DVT[23]. The subjects of this study are elderly patients 50 years and older. The elasticity of blood vessels are poor and elder patients are complicated by the physiological or organic changes of multiple organs, and the perioperative period of lower extremity joint mobility and the amount of activity are significantly reduced, so the risk of DVT is higher[24-26]. We have found that age $>70 y, \quad B M I \geq 28$, diabetes, bilateral joint replacements, duration of surgery $\geq 120 \mathrm{~min}$, cemented prosthesis, and duration of days in bed $>3$ days were the independent risk factors of DVT of lower limb in patients with THA. It is clinically necessary to carry out early prevention and intervention for these risk factors of DVT to reduce the occurrence of DVT.

With the increase of age, the elasticity of blood vessels in patients decreases, the blood vessel walls are easily damaged, and elderly patients are prone to have primary diseases such as diabetes, which increases the incidence of DVT[27]. The results of our study are consistent with the findings of previous studies. BMI is a factor that affects the occurrence of DVT after surgery, which has been confirmed by many studies[28-30]. The guidelines set $\mathrm{BMI} \geq 30 \mathrm{~kg} / \mathrm{m}^{2}$ as an influencing factor of DVT. WHO uses BMI $\geq 30 \mathrm{~kg} / \mathrm{m}^{2}$ as the obesity standard[31], and the WHO Western Pacific Region and the International Working Group recommend that for the Asian population $\mathrm{BMI}>25 \mathrm{~kg} / \mathrm{m}^{2}$ is taken as obesity [32]. Experts from the Chinese Obesity Working Group considered that $\mathrm{BMI} \geq 28 \mathrm{~kg} / \mathrm{m} 2$ is more appropriate for obesity[33], this study used the standard of BMI $\geq 28 \mathrm{~kg} /$ $\mathrm{m}^{2}$, the results have showed that $\mathrm{BMI} \geq 28 \mathrm{~kg} / \mathrm{m}^{2}$ is a risk factor affecting the occurrence of DVT. Therefore, for patients with $\mathrm{BMI}>28$, DVT should be warned in advance.

Many studies[34, 35] have reported that diabetes is a risk factor for DVT. Orthopedic surgery patients are in a state of stress. Diabetic patients' blood glucose changes more than that of non-diabetic patients[36]. A large number of cytokines are released in the body during surgery, which easily activates the endogenous and exogenous coagulation system and increases the risk of thrombosis[37]. The results of this study suggest that blood glucose control in patients with THA perioperative should be strengthened to reduce the incidence of DVT. For patients with cemented prostheses, intraoperative bone cement can cause the release of mononuclear cytokines and the deformation and separation of endothelial cells, further covering the endothelial surface with fibrinogen, which in turn activates the exogenous blood coagulation pathway, resulting in high blood coagulation state, thereby increasing the risk of DVT[38]. Elderly patients with hip replacement are weak and require bed rest. Slow blood flow in the lower limb can also increase the risk of DVT[39]. The results of this study show that

Table 3 The logistic regression analysis on the risk factors of DVT in patients with THA

\begin{tabular}{llllll}
\hline Variables & $\boldsymbol{\beta}$ & $\mathbf{S} \mathbf{x}$ & OR & $\mathbf{9 5} \% \mathbf{C l}$ \\
\hline Age $>$ 70y & 0.133 & 0.227 & 4.406 & $1.744 \sim 6.134$ & $\mathbf{p}$ \\
BMI $\geq 28$ & 0.119 & 0.230 & 0.016 \\
Diabetes & 0.103 & 0.151 & 3.275 & $1.181 \sim 4.531$ & 0.023 \\
Bilateral joint replacements & 0.147 & 0.183 & $2.274 \sim 5.279$ & $1.402 \sim 4.423$ \\
Duration of surgery $\geq 120$ min & 0.149 & 0.102 & 3.081 & $1.293 \sim 5.308$ & 0.033 \\
Cemented prosthesis & 0.126 & 0.117 & 2.435 & $1.104 \sim 4.315$ & 0.026 \\
Duration of days in bed $>$ 3 days & 0.113 & 0.124 & 1.566 & $1.182 \sim 1.994$ & 0.042 \\
\hline
\end{tabular}


the days in bed $\geq 3$ days after surgery is a risk factor for DVT. Therefore, it should be as early as possible to perform functional exercises of the lower limb to promote blood return to the lower limb and reduce the risk of thrombosis.

The prevention and treatment of DVT is of great significance to the prognosis of patients. It is necessary for doctors and nurses to strengthen preoperative assessment. Before surgery, it is necessary to understand the patient's past medical history, general condition and blood coagulation, strengthen the screening of high-risk patients with DVT, and actively correct the effects of anemia, hypertension, diabetes and other cardiovascular diseases[40]. During the operation, the doctor should be familiar with the anatomy and surgical techniques, and reduce the operation and anesthesia duration. And the operation should be gentle and meticulous, and reduce unnecessary tissue damage, especially the intraoperative blood vessel damage, so as not to damage the vascular intima and induce thrombosis[41]. After the operation, the affected limb should be raised in certain position, and functional exercise should be performed as early as possible to increase venous blood return. Besides, the patients should regulate mood, eat lightly, and maintain smooth stools to reduce the obstruction of lower limb venous return caused by forced defecation and increased abdominal pressure[42, 43].

Several limitations must be concerned in this present study. Firstly, it is worth noting that the sample size of cases selected in this study is small and our study is a single-center study. The results of the study should be treated with caution. Secondly, patient risk stratification is a valid initial approach to ensure better management of patients undergoing THA and to predict who can benefit from a pharmacological preventive strategy, we did not perform individual thromboembolic risk before surgery in this present study. Thirdly, hyperglycemia has been found to be associated with many postoperative complications, in our clinical practice, we would correct the hyperglycemia before surgery. However, we did not detect the glycated hemoglobin routinely, since our study is a retrospective design, we could not collect the most data on the glycated hemoglobin, therefore we could not include those indicators for analysis. Besides, other factors including infections, medications, cancer, trauma and smoking et al. play a significant role in the total amount of post-surgical complications, limited by data, we did not investigate those factors in this present study, more studies on the association of those factors and postoperative DVT are needed. Future studies with larger samples and multicenters need to further explore the risk factors of DVT in patients undergoing THA, to provide reliable evidence to the prophylaxis of DVT.

\section{Conclusions}

In summary, the occurrence of DVT after THA is associated with many factors. In clinical work, attention should be paid to identify the risk factors that induce DVT and actively intervening are needed. The heath care provider should take effective measures targeted on the risk factors in time, and to guide patients to early perform functional exercises to reduce the incidence of DVT, thereby increasing the efficacy of THA and improving the life quality of patients.

\section{Abbreviations \\ DVT: deep vein thrombosis; THA: total hip arthroplasty}

\section{Acknowledgements}

None.

Authors' contributions

$R N$ designed research; $X Y, Y W, R N$ conducted research; $X Y, R N$ analyzed data; $X Y, R N$ wrote the first draft of manuscript; $R N$ had primary responsibility for final content. All authors read and approved the final manuscript.

Funding

None.

Availability of data and materials

All data generated or analyzed during this study are included in this published article.

\section{Declarations}

Ethics approval and consent to participate

In this study, all methods were performed in accordance with the relevant guidelines and regulations. Our study had been verified and approved by the ethics committee of The Third Affiliated Hospital of Anhui Medical University (No.1700342), and all the included patients had signed the written informed consents.

\section{Consent for publication}

Not applicable.

\section{Competing interest}

The authors declare that they have no competing interests.

Received: 18 February 2021 Accepted: 10 May 2021

Published online: 15 June 2021

\section{References}

1. Pfluger MJ, Fromel DE, Meurer A: Total Hip Arthroplasty Revision Surgery: Impact of Morbidity on Perioperative Outcomes. J Arthroplasty 2021, 36(2):676-681.

2. Shapira J, Chen SL, Rosinsky PJ, Maldonado DR, Lall AC, Domb BG: Outcomes of outpatient total hip arthroplasty: a systematic review. Hip Int 2021, 31(1):4-11.

3. Pollock M, Somerville L, Firth A, Lanting B: Outpatient Total Hip Arthroplasty, Total Knee Arthroplasty, and Unicompartmental Knee Arthroplasty: A Systematic Review of the Literature. JBJS Rev 2016, 4(12): 01874474-201612000-00004.

4. Tan Z, Cao G, Wang G, Zhou Z, Pei F: Total hospital cost, length of stay, and complications between simultaneous and staged bilateral total hip arthroplasty: A nationwide retrospective cohort study in China. Medicine (Baltimore) 2019, 98(11):e14687.

5. Shi XT, Li CF, Cheng CM, Feng CY, Li SX, Liu JG: Preoperative Planning for Total Hip Arthroplasty for Neglected Developmental Dysplasia of the Hip. Orthop Surg 2019, 11(3):348-355. 
6. Li J, Zhu H, Liao R: Enhanced recovery after surgery (ERAS) pathway for primary hip and knee arthroplasty: study protocol for a randomized controlled trial. Trials 2019, 20(1):599.

7. Wainwright TW, Gill M, McDonald DA, Middleton RG, Reed M, Sahota O, Yates $\mathrm{P}$, Ljungqvist $\mathrm{O}$ : Consensus statement for perioperative care in total hip replacement and total knee replacement surgery: Enhanced Recovery After Surgery (ERAS((R))) Society recommendations. Acta Orthop 2020, 91(1):3-19.

8. Matharu GS, Kunutsor SK, Judge A, Blom AW, Whitehouse MR: Clinical Effectiveness and Safety of Aspirin for Venous Thromboembolism Prophylaxis After Total Hip and Knee Replacement: A Systematic Review and Meta-analysis of Randomized Clinical Trials. JAMA Intern Med 2020, 180(3):376-384.

9. Falck-Ytter Y, Francis CW, Johanson NA, Curley C, Dahl OE, Schulman S, Ortel TL, Pauker SG, Colwell CW, Jr.: Prevention of VTE in orthopedic surgery patients: Antithrombotic Therapy and Prevention of Thrombosis, 9th ed: American College of Chest Physicians Evidence-Based Clinical Practice Guidelines. Chest 2012, 141(2 Suppl):e278S-e325S.

10. Nadi S, Vreugdenburg TD, Atukorale Y, Ma N, Maddern G, Rovers M: Safety and effectiveness of aspirin and enoxaparin for venous thromboembolism prophylaxis after total hip and knee arthroplasty: a systematic review. ANZ J Surg 2019, 89(10):1204-1210.

11. Warren JA, Sundaram K, Anis HK, Kamath AF, Higuera CA, Piuzzi NS: Have Venous Thromboembolism Rates Decreased in Total Hip and Knee Arthroplasty?J Arthroplasty 2020, 35(1):259-264.

12. Kim JS: Deep Vein Thrombosis Prophylaxis after Total Hip Arthroplasty in Asian Patients. Hip Pelvis 2018, 30(4):197-201.

13. Chari A, Khokhar A, Murray D, McNally M, Pandit H: Venous thromboembolism and its prophylaxis in elective total hip arthroplasty: an international perspective. Hip Int 2012, 22(1):1-8

14. Colwell CW: The ACCP guidelines for thromboprophylaxis in total hip and knee arthroplasty. Orthopedics 2009, 32(12 Suppl):67-73.

15. Tian Q, Li M: Risk factors of deep vein thrombosis of lower extremity in patients undergone gynecological laparoscopic surgery: what should we care. BMC Womens Health 2021, 21(1):130.

16. Millar JS, Lawes CM, Farrington B, Andrew P, Misur P, Merriman E, Walker M: Incidence of venous thromboembolism after total hip, total knee and hip fracture surgery at Waitemata District Health Board following a peerreviewed audit. N Z Med J 2020, 133(1511):52-60.

17. Zeng GJ, Xu S, Pang HN: Incidence of deep vein thrombosis and pulmonary embolism in Asian patients after direct anterior total hip arthroplasty. J Orthop 2020, 21:528-531.

18. Kawai T, Goto K, Kuroda Y, Matsuda S: Lower Activity and Function Scores Are Associated with a Higher Risk of Preoperative Deep Venous Thrombosis in Patients Undergoing Total Hip Arthroplasty. J Clin Med 2020, 9(5):1257.

19. Santana DC, Emara AK, Orr MN, Klika AK, Higuera CA, Krebs VE, Molloy RM, Piuzzi NS: An Update on Venous Thromboembolism Rates and Prophylaxis in Hip and Knee Arthroplasty in 2020. Medicina (Kaunas) 2020, 56(9):416.

20. Wainwright TW, Burgess LC, Middleton RG: A Single-Centre Feasibility Randomised Controlled Trial Comparing the Incidence of Asymptomatic and Symptomatic Deep Vein Thrombosis Between a Neuromuscular Electrostimulation Device and Thromboembolism Deterrent Stockings in Post-Operative Patients Recovering From Elective Total Hip Replacement Surgery. Surg Technol Int 2020, 36:289-298.

21. Kumazaki R, Imai N, Sakagami A, Hirano Y, Suzuki H, Endo N: Passive ankle motion and calf massage without anticoagulation therapy after total hip arthroplasty: A retrospective study. J Orthop Sci 2020, 12:18;509492658(20)30337-7.

22. Nemeth B, Nelissen R, Arya R, Cannegieter S: Preventing VTE following total hip and knee arthroplasty: Is prediction the future?J Thromb Haemost 2021, 19(1):41-45.

23. ang A, Sicat CS, Singh V, Rozell JC, Schwarzkopf R, Long WJ: Aspirin Use for Venous Thromboembolism Prevention Is Safe and Effective in Overweight and Obese Patients Undergoing Revision Total Hip and Knee Arthroplasty. J Arthroplasty 2020, 11:S0883-5403(20)31245-6.

24. Mihara M, Tamaki Y, Nakura N, Takayanagi S, Saito A, Ochiai S, Hirakawa K: Clinical efficacy of risk-stratified prophylaxis with low-dose aspirin for the management of symptomatic venous thromboembolism after total hip arthroplasty. J Orthop Sci 2020, 25(1):156-160.
25. Sloan M, Lee GC: Mortality and Complications in Patients with Metastatic Disease after Primary Total Hip and Total Knee Arthroplasty. J Arthroplasty 2020, 35(12):3512-3516.

26. Tang A, Zak S, lorio R, Slover J, Bosco J, Schwarzkopf R: Low-Dose Aspirin Is Safe and Effective for Venous Thromboembolism Prevention in Patients Undergoing Revision Total Hip Arthroplasty: A Retrospective Cohort Study. J Arthroplasty 2020, 35(8):2182-2187.

27. Kahn SR, Shivakumar S: What's new in VTE risk and prevention in orthopedic surgery. Res Pract Thromb Haemost 2020, 4(3):366-376.

28. Gonzalez Della Valle A, Shanaghan KA, Nguyen J, Liu J, Memtsoudis S, Sharrock NE, Salvati EA: Multimodal prophylaxis in patients with a history of venous thromboembolism undergoing primary elective hip arthroplasty. Bone Joint J 2020, 102-B(7_Supple_B):71-77.

29. Yang Y, Li Z, Liang H, Tian J: Association between metabolic syndrome and venous thromboembolism after total joint arthroplasty: a metaanalysis of cohort studies. J Orthop Surg Res 2020, 15(1):570.

30. Sodhi N, Anis HK, Acuna AJ, Vakharia RM, Piuzzi NS, Higuera CA, Roche MW, Mont MA: The Effects of Opioid Use on Thromboembolic Complications, Readmission Rates, and 90-Day Episode of Care Costs After Total Hip Arthroplasty. J Arthroplasty 2020, 35(6S):S237-S240.

31. Apovian CM: Obesity: definition, comorbidities, causes, and burden. Am J Manag Care 2016, 22(7 Suppl):s176-185.

32. WHO: The Asia-Pacific perspective: redefining obesity and its treatment: Geneva: WHO; 2000.

33. Association OBoCM: Guidelines for venous thromboembolism in major orthopedic surgery in China. Chinese Journal of Orthopaedics 2016, 36(2): 65-71.

34. Sloan M, Sheth N, Lee GC: Is Obesity Associated With Increased Risk of Deep Vein Thrombosis or Pulmonary Embolism After Hip and Knee Arthroplasty? A Large Database Study. Clin Orthop Relat Res 2019, 477(3): 523-532.

35. El-Menyar A, Asim M, Al-Thani H: Obesity Paradox in Patients With Deep Venous Thrombosis. Clin Appl Thromb Hemost 2018, 24(6):986-992.

36. Davies HO, Popplewell M, Singhal R, Smith N, Bradbury AW: Obesity and lower limb venous disease - The epidemic of phlebesity. Phlebology 2017, 32(4):227-233

37. Wang L, Duan S, Liao D, Luo Z, Hou X: [Effect of different use time of intermittent pneumatic compression on the incidence of deep vein thrombosis of lower extremities after arthroplasty]. Zhongguo Xiu Fu Chong Jian Wai Ke Za Zhi 2020, 34(5):585-590.

38. Mao $Y$, Ning $C$, Miaomiao $L$ : Analysis of influencing factors of deep vein thrombosis of lower limbs in elderly patients undergoing hip replacement. Journal of Practical Orthopaedics 2020, 26(1):8-11.

39. Zeng C, Bennell K, Yang Z, Nguyen UDT, Lu N, Wei J, Lei G, Zhang Y: Risk of venous thromboembolism in knee, hip and hand osteoarthritis: a general population-based cohort study. Ann Rheum Dis 2020, 79(12):16161624

40. Kittle H, Ormseth A, Patetta MJ, Sood A, Gonzalez MH: Chronic Corticosteroid Use as a Risk Factor for Perioperative Complications in Patients Undergoing Total Joint Arthroplasty. J Am Acad Orthop Surg Glob Res Rev 2020, 4(7):e2000001.

41. Bawa H, Weick JW, Dirschl DR, Luu HH: Trends in Deep Vein Thrombosis Prophylaxis and Deep Vein Thrombosis Rates After Total Hip and Knee Arthroplasty. J Am Acad Orthop Surg 2018, 26(19):698-705.

42. Wilson DG, Poole WE, Chauhan SK, Rogers BA: Systematic review of aspirin for thromboprophylaxis in modern elective total hip and knee arthroplasty. Bone Joint J 2016, 98-B(8):1056-1061.

43. Lieberman JR, Hsu WK: Prevention of venous thromboembolic disease after total hip and knee arthroplasty. J Bone Joint Surg Am 2005, 87(9): 2097-2112.

\section{Publisher's Note}

Springer Nature remains neutral with regard to jurisdictional claims in published maps and institutional affiliations. 